\title{
The Inhibitory Effect of Mouse Gastric DNA on Amplification of Helicobacter pylori Genomic DNA in Quantitative PCR
}

\author{
Mehdi Alikhani ${ }^{1}$, Ebrahim Shafaie ${ }^{1}$, Esmat Mirabzadeh Ardakani ${ }^{2}$, Maryam \\ Esmaeili ${ }^{1}$, Samaneh Saberi ${ }^{1}$, Mojgan Hatefi ${ }^{1}$ and Marjan Mohammadi ${ }^{*}$ \\ ${ }^{1}$ HPGC Research Group, Medical Biotechnology Department, Pasteur Institute of Iran, Tehran, Iran; \\ ${ }^{2}$ Animal Sciences Lab, Department of Molecular Medicine, Pasteur Institute of Iran, Tehran, Iran
}

Received 18 June 2018; revised 30 June 2018; accepted 4 July 2018

\begin{abstract}
Background: Quantitation of Helicobacter pylori $(\mathrm{Hp})$ in the gastric tissue is essential for assessment of vaccination/therapeutic regimens. Methods \& Results: Here, the inhibitory effect of mouse gastric DNA (MgDNA) on amplification of $\mathrm{Hp}$ genomic DNA (HpDNA) was evaluated by spiking HpDNA with serial dilutions of MgDNA, which yielded concentrations of $>10 \mathrm{ng} / \mu \mathrm{l}$ and $>0.63-10 \mathrm{ng} / \mu \mathrm{l}$ of MgDNA, as inhibition and interference zones, respectively. Mice were then inoculated with varying doses of $\mathrm{Hp}$ and assessed at the inhibition-free concentration of $0.63 \mathrm{ng} / \mu \mathrm{l}$. The average $\mathrm{Hp}$ copy numbers per microgram of gastric tissue discriminated mice having received high vs. low dose inoculums $(p<0.001)$. Secondly, Hp copy numbers were quantitated in immunized mice, which demonstrated significantly lower numbers, in reference to controls $(p=0.006)$. Conclusion: Our method, bypassing the inhibition and/or interference imposed by MgDNA, was able to quantitate gastric tissue-colonizing $\mathrm{Hp}$, segregating mice inoculated with low vs. high doses of $\mathrm{Hp}$, as well as those immunized from controls. DOI: 10.29252/ibj.23.4.297
\end{abstract}

Keywords: Amplification, Inhibition, Interference, Standard curve, Quantitative PCR

Corresponding Author: Marjan Mohammadi

HPGC Research Group, Department of Medical Biotechnology, Pasteur Institute of Iran, No. 69, Pasteur Ave., Tehran 1316943551, Iran;

E-mail: marjan.mohammadi@pasteur.ac.ir, marjan.mohammadi2010@gmail.com

The first and the second authors contributed equally to this work and share first authorship.

\section{INTRODUCTION}

$\mathrm{T}$ he success rate of any Helicobacter pylori (Hp)related trial vaccination and/or therapeutic regimens is ultimately determined by quantitating the actual bacterial load, colonizing the gastric tissue. Several methods have been introduced for this objective, most of which have employed quantitative PCR (qPCR) to determine $\mathrm{Hp}$ genome copy numbers. The $\operatorname{glmM}$ (ureC) gene of $\mathrm{Hp}$ is most suitable for this purpose, as it is fully conserved and is present in one single copy ${ }^{[1]}$. However, the inhibiting and/or interfering effect of mammalian genomic DNA poses serious problems. Loddenkötter and colleagues ${ }^{[2]}$ have reported a qPCR method, quantitating as few as
30 copy numbers of $g \operatorname{lm} M$, in the presence of excess human DNA. Roussel et al. ${ }^{[3]}$, on the other hand, evaluated the efficiency of the quantitation of Hp 16S rDNA in mouse gastric tissue, by focusing on the extraction method, and found host DNA inhibition at minimum, when mouse tissue was homogenized by glass beads, and its DNA was extracted via commercial kits. These authors found relative quantitation (Hp/mouse genome) preferable to the absolute standard curve quantitation method ${ }^{[3]}$. Having used the relative method, Molnar et al. ${ }^{[4]}$ observed a significant correlation with urea breath test results in infected patients and revealed higher density of colonization, in gastric regions with erosions. In 2012, Belda et al. ${ }^{[5]}$ reported that the diagnostic accuracy of qPCR in 
detecting infected patients varied based on the anatomic region of the stomach, ranging from "very good" (AUC $=0.83$ ) in the corpus to "excellent" (AUC $=0.91)$ in the antrum. Kargar et al. ${ }^{[6]}$ added the analysis of point mutations in the $23 \mathrm{~S}$ rRNA gene to the quantitation of $16 \mathrm{~S}$ rRNA, to detect not only the bacterial load but also the rate of molecular resistance against clarithromycin. Quantitation of $\mathrm{Hp}$ in the gastric tissue is also of critical use, when the gastric tissue is contaminated with blood (i.e. in patients with upper gastrointestinal bleeding), which distorts the accuracy of routine diagnostic tests, such as rapid urease test (RUT) ${ }^{[7]}$. Here, we have assessed the inhibiting/interfering effect of mouse gastric DNA (MgDNA) on the quantitation of the colonizing $\mathrm{Hp}$ copy numbers and have been able to determine an inhibition-free threshold.

\section{MATERIALS AND METHODS}

\section{Cloning of $\operatorname{glm} M$}

The $g \operatorname{lm} M$ (ureC) gene fragment (978 bp) of Hp was cloned into pTG19T vector (Vivantis, Malaysia) following its amplification by High-Fidelity DNA polymerase (TransTaq, TransGen Biotech, China), using glm $M$-specific primers (F: 5'- GAT GGC GTG AGG GGT AAA G-3' and R: 5'-GATATG CCC GCT TTG CTC-3'), under the following conditions: $4 \mathrm{~min}$ at $94{ }^{\circ} \mathrm{C}$ as initial denaturation, followed by 30 cycles of $60 \mathrm{~s}$ at $94{ }^{\circ} \mathrm{C}$ for denaturation, $30 \mathrm{~s}$ at $57.4{ }^{\circ} \mathrm{C}$ as annealing, $60 \mathrm{~s}$ at $72{ }^{\circ} \mathrm{C}$ for extension, and final extension at $72{ }^{\circ} \mathrm{C}$ for $10 \mathrm{~min}$. The recombinant pTG19T-glm $M$ vector was transformed into fresh competent $E$. coli TOP10F' strain (Invitrogen, USA) and cultured on LB agar plates, supplemented with 100 $\mu \mathrm{g} / \mathrm{ml}$ of ampicillin, $15 \mu \mathrm{g} / \mathrm{ml}$ of tetracycline, $1 \mathrm{mM}$ of isopropyl B-D-1-thiogalactopyranoside (IPTG), and 40 $\mu \mathrm{g} / \mathrm{ml}$ of X-gal. The Blue-white screening was performed to select $g \operatorname{lm} M$-positive clones. The cloning procedure was further confirmed by PCR and enzymatic (BamHI) digestion.

\section{Generation of standard curves}

The circular pTG19T-glm $M$ vector was linearized by $X b a I$ enzyme, and its mean concentration was determined by $\mathrm{OD}_{260}$ measurement, in triplicates (Epoch Microplate spectrophotometer, USA). The mass and copy number of pTG19T-glmM was calculated by the Applied Biosystems (ABI, USA) recommended formula ${ }^{[8]}$ : Mass $=($ plasmid size $[\mathrm{bp}]) \times$ $\left(1.096 \times 10^{-21}\right)$. Since there was a single copy of the glmM gene in each plasmid template (PT) and Hp genomic DNA (HpDNA), the mass required for the preparation of serial copy number dilutions (range: 10-
$10^{9}$ copies) was calculated. HpDNA was extracted by DNA extraction kit (MN, Germany), and the required DNA for serial dilutions (10-10 ${ }^{8}$ of HpDNA copies) was prepared, as mentioned for PT, keeping in mind that the average size of HpDNA is $1.6 \mathrm{Mb}$.

\section{Quantitative real-time PCR}

Serial dilutions of PT and HpDNA underwent amplification by qPCR, which was performed in total reaction volumes of $10 \mu \mathrm{l}$, containing $5 \mu \mathrm{l}$ of Fast SYBR® Green Master Mix (ABI, USA), 5 pM of each glm $M$ primer (RT-F: 5' ATG TTT GTG ATG CGT TTA 3' and RT-R: 5' AGC CTA TGG AAG TGA GAG 3'), and DNA templates (serial dilutions of PT, HpDNA, and MgDNA). qPCR was conducted by Applied Biosystems StepOne ${ }^{T M}$ Real-Time PCR Systems, under the following conditions: $14 \mathrm{~min}$ at 95 ${ }^{\circ} \mathrm{C}$ as initial denaturation, followed by 50 cycles of $15 \mathrm{~s}$ at $95{ }^{\circ} \mathrm{C}$ for denaturation, and $60 \mathrm{~s}$ at $60{ }^{\circ} \mathrm{C}$ for annealing and extension. Melting curve analysis was assessed for the $60-95{ }^{\circ} \mathrm{C}$ temperature range, and the cycle threshold $(\mathrm{Ct})$ was calculated by StepOne v3.2 software (ABI, USA).

\section{The inhibitory effect of mouse gastric DNA}

The inhibiting role of $\mathrm{MgDNA}$ on $\operatorname{glm} M$ gene amplification was investigated via spiking $10^{5}$ copies of PT and HpDNA, with 14 serial dilutions (0-20 $n g / \mu l)$ of MgDNA in qPCR reaction and co-amplified, as mentioned above. The inhibiting impact of MgDNA was investigated by $\mathrm{Ct}$ calculation and copy number quantitation, in the presence of various concentrations.

\section{Quantitation of Hp copy numbers in mice}

Three groups of 4-6-week-old female C57BL/6 mice (five per group) were orally inoculated thrice in three consecutive days with different doses $\left(3 \times 10^{4}, 3 \times 10^{5}\right.$, and $3 \times 10^{6} \mathrm{CFU} /$ mouse) with mouse-adapted $\mathrm{Hp}$. Immunization was performed, as described previously ${ }^{[9]}$, with minor modifications ${ }^{[10]}$. Briefly, mice were orally intubated with inoculums containing $10 \mu \mathrm{g}$ of cholera toxin and $100 \mu \mathrm{g}$ of recombinant Urease B subunit (UreB) ${ }^{[11]}$, in $250 \mu$ l of gavage buffer $(0.5 \%$ casein hydrolysate, $0.2 \mathrm{~mol} / \mathrm{L}$ of sodium bicarbonate, and $0.5 \%$ glucose in PBS), thrice with two-week intervals. The sham-immunized control group received only the gavage buffer. Two weeks following the last immunization, both groups were inoculated with $3 \times 10^{5} \mathrm{CFU}$ of 24-hour old, liquid cultured $\mathrm{Hp}^{[12]}$, and sacrificed two weeks thereafter. At sacrifice, mouse stomachs were longitudinally divided into two parts for: (1) RUT and (2) DNA extraction. RUT color development was documented at $4 \mathrm{~h}$. Total DNA was extracted from snap-frozen tissue by a 
commercial kit (MN, Germany). Optimized concentrations were used for quantitation of the tissuecolonizing $\mathrm{Hp}$ by qPCR. Standard curves of PT and HpDNA were employed to calculate the Hp copy numbers per microgram of gastric tissue.

\section{RESULTS}

\section{Generation of standard curves}

Gene-specific amplification was successful for $10^{1}$.
$10^{9}$ copies of PT. Regression analysis showed a linear pattern of $\mathrm{Ct}$ for $10^{2}-10^{7}$ copy numbers of PT, with a correlation coefficient $\left(\mathrm{R}^{2}\right)$ of $>0.99$ (Fig. 1A and 1B). The same was applied for HpDNA gene-specific quantitation, which amplified $10^{1}-10^{7}$ copy numbers of HpDNA and demonstrated a linear pattern for $10^{2}-10^{6}$ copies of HpDNA ( $\mathrm{R}^{2}>0.99$, Figs. $1 \mathrm{C}$ and 1D). Considering the fact that SYBR Green binds to doublestranded DNA, SYBR Green-based qPCR is unable to discriminate between specific and non-specific PCR products. However, our melting curve analysis
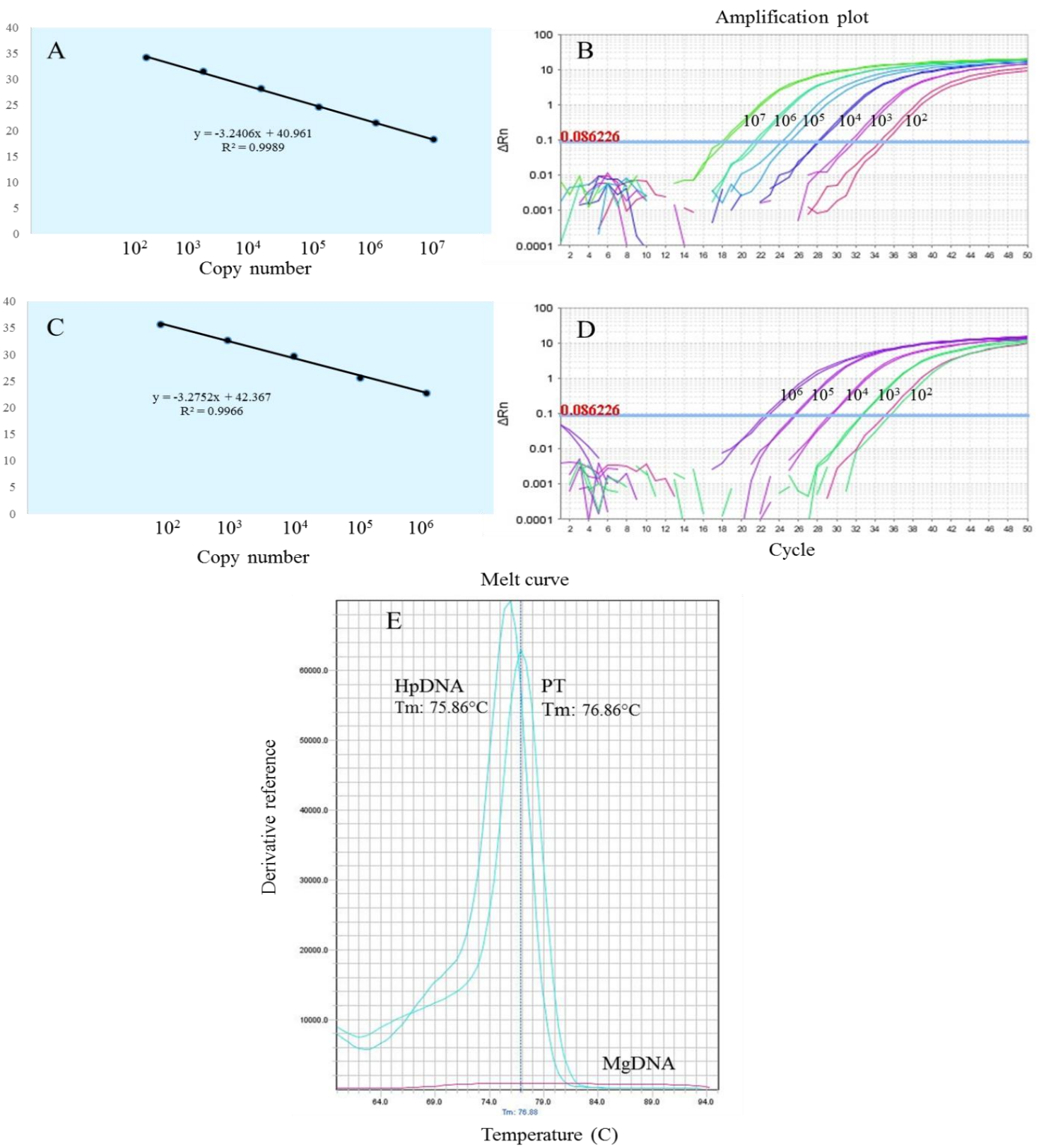

Fig. 1. Standard curves for $g \operatorname{lm} M$ plasmid template (PT) and HpDNA. (A) Linear regression of PT, (B) the amplification plot of PT serial dilutions, (C) linear regression of HpDNA, (D) the amplification of HpDNA serial dilutions, and (E) melting curve analysis for PT, HpDNA, and MgDNA. 


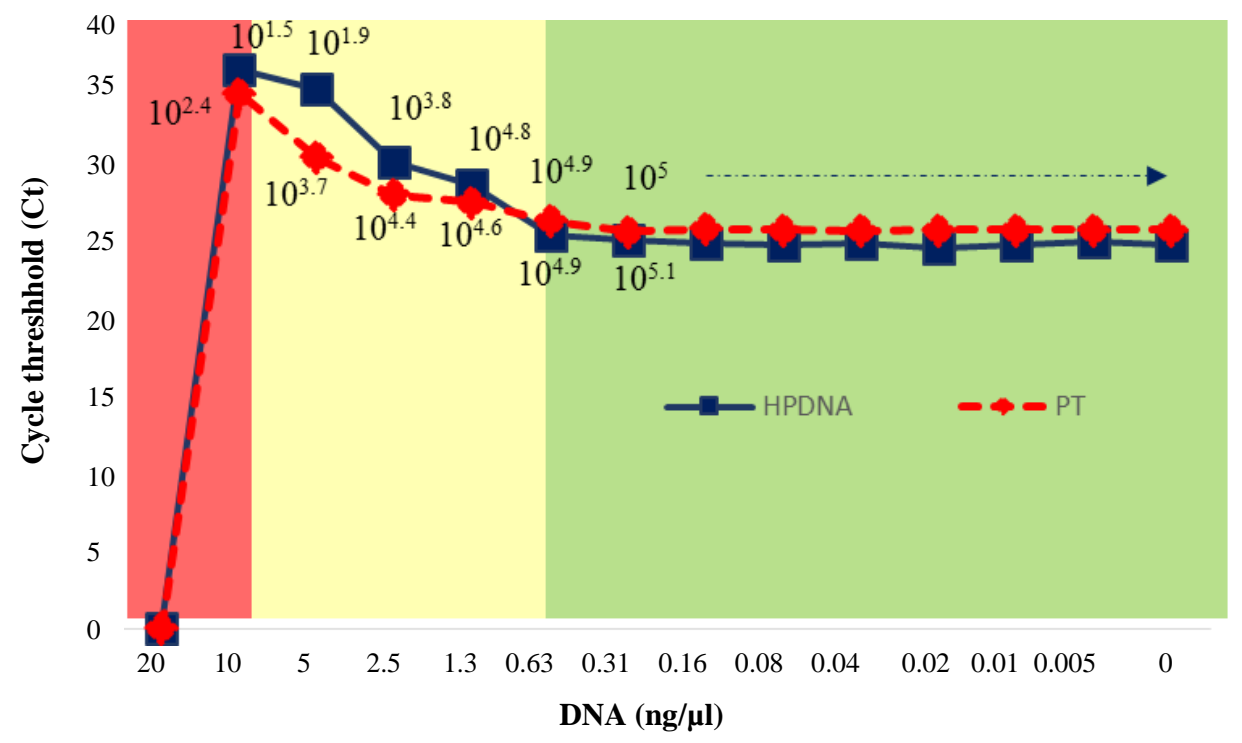

Fig. 2. The inhibitory effect of MgDNA on amplification of PT and HpDNA cycle threshold (Ct) and the resulting copy numbers of PT (dotted line) and HpDNA (solid line), in the presence of 0-20 ng/ $\mu \mathrm{l}$ of MgDNA; the inhibition ( $>10 \mathrm{ng} / \mu \mathrm{l})$, interference (>0.63-10 $\mathrm{ng} / \mu \mathrm{l})$, and inhibition-free $(\leq 0.63 \mathrm{ng} / \mu \mathrm{l})$ zones are denoted.

confirmed the specificity of the amplified $\operatorname{glm} M$ gene product, with melting temperatures of $76.86{ }^{\circ} \mathrm{C}$ for PT and $75.86{ }^{\circ} \mathrm{C}$ for HpDNA, whereas no melting temperature was observed for MgDNA (Fig. 1E).

The inhibitory effect of MgDNA on the amplification of PT and HpDNA

In order to assess the inhibitory effect of MgDNA on amplification of PT and HpDNA, $10^{5}$ copies of each were spiked with 14 serial dilutions of MgDNA (0-20 $\mathrm{ng} / \mu \mathrm{l})$. This analysis revealed (1) inhibition (>10 $\mathrm{ng} / \mu \mathrm{l})$, (2) interference (>0.63-10 $\mathrm{ng} / \mu \mathrm{l})$, and (3) inhibition-free $(\leq 0.63 \mathrm{ng} / \mu \mathrm{l})$ zones, which coincided for both PT and HpDNA amplification (Fig. 2).

\section{Quantitation of Hp copy numbers in mice}

The sensitivity of our method was evaluated by the quantitation of the colonizing $\mathrm{Hp}$ in groups of mice, inoculated with varying doses of Hp: (Group A) $3 \times 10^{4}$, (Group B) $3 \times 10^{5}$, and (Group C) $3 \times 10^{6}$ CFU. According to RUT results, every tissue sample underwent color changes with varying intensities
(A)

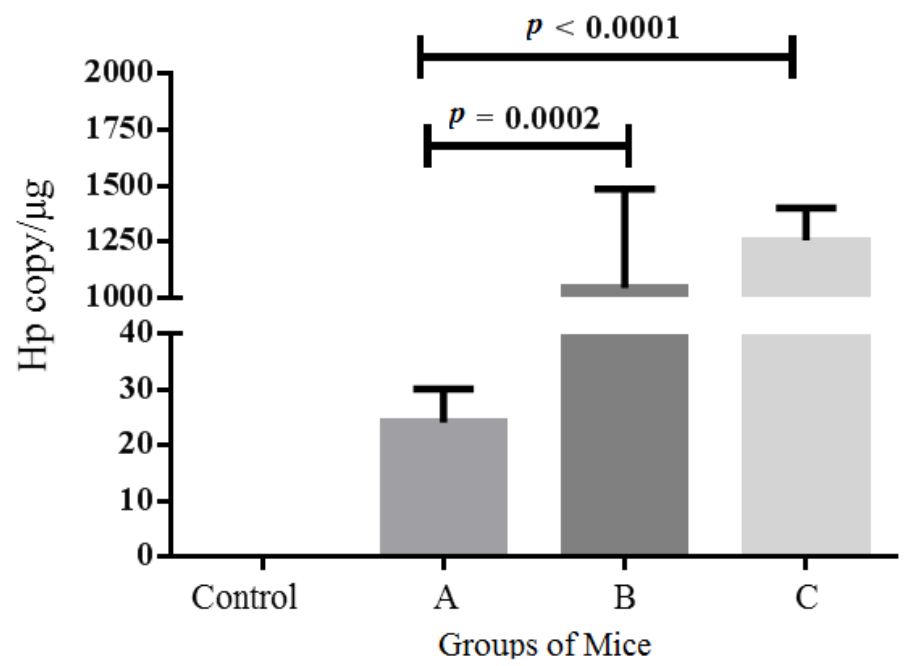

(B)

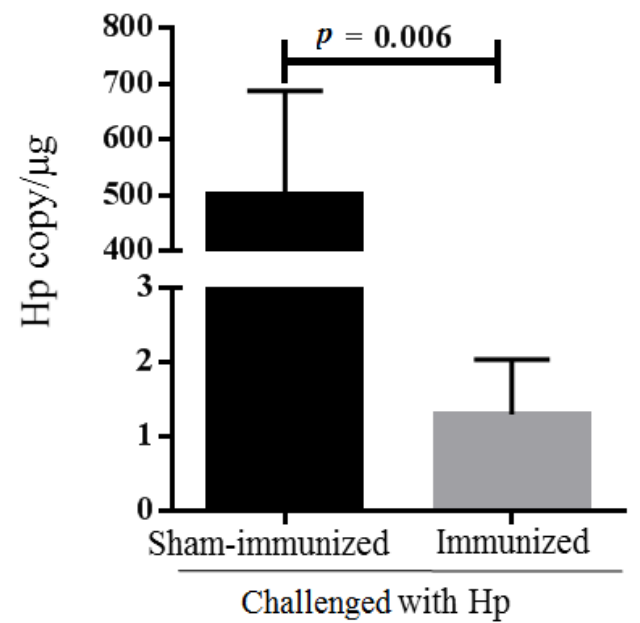

Fig. 3. Quantitation of Hp copy numbers in the mouse gastric tissue. (A) Groups of mice inoculated with $3 \times 10^{4}(\mathrm{Group} A), 3 \times 10^{5}$ (Group B), and $3 \times 10^{6}$ (Group C) CFU of Hp, in comparison with uninfected controls. (B) Groups of immunized vs. sham-immunized control mice, challenged with Hp. 
over time, ranging from lowest (Group A) to highest (Group C). Keeping in mind the highest inhibition-free concentration of MgDNA, we quantitated Hp copy number in $0.63 \mathrm{ng} / \mu \mathrm{l}$ of mouse gastric DNA. Accordingly, the average $\mathrm{Hp}$ copy numbers per microgram of gastric tissue for each group of mice was ascertained as: (Group A) $24 \pm 6$, (Group B) $1042 \pm$ 442, and (Group C) $1255 \pm 145$, which discriminated mice in group A from those in groups B $(p=0.0002)$ and $\mathrm{C}(p<0.0001$, Fig. 3A). Thereafter, we employed this concentration of MgDNA $(0.63 \mu \mathrm{g} / \mathrm{ml})$ to quantitate Hp copy numbers in a vaccine-mouse model. For this purpose, immunized (UreB + cholera toxin) and sham-immunized mice were challenged with $\mathrm{Hp}$ and sacrificed two weeks later. RUT test results exhibited a highly intense color development for the sham-immunized mice, whereas the immunized mice revealed no color change. Once again, $0.63 \mathrm{ng} / \mu \mathrm{l}$ of MgDNA underwent Hp copy number quantitation per microgram of gastric tissue and yielded significantly lower copy numbers for immunized mice $(1.2 \pm 0.7)$, as compared to the controls $(499 \pm 187, p=0.006$, Fig. 3B).

\section{DISCUSSION}

Quantitation of $\mathrm{Hp}$ in gastric tissue plays an essential role in the evaluation of any vaccination and/or therapeutic regimens. There are various molecular methods for Hp quantitation in biological samples, such as competitive $\mathrm{PCR}^{[13]}$, noncompetitive $\mathrm{PCR}^{[14]}$, and fluorescence-based PCR technology (real-time PCR $)^{[5,7]}$. The major cause of PCR failure is the presence of PCR inhibitors, which can lead to falsenegative results ${ }^{[15]}$. In this study, we have extensively evaluated the inhibitory effect of MgDNA on HpDNA amplification. It is known that the amplification of DNA from colonized $\mathrm{Hp}$ in gastric tissue is inhibited by gastric tissue $\mathrm{DNA}^{[3,16]}$. Inhibition in real-time PCR can result from PCR inhibitors within extraction reagents ${ }^{[3]}$ and from excess of non-target DNA

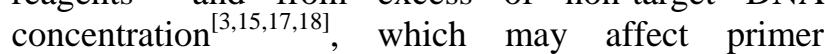
annealing efficiency and interference with SYBR Green I to dsDNA binding ${ }^{[15]}$. The most common method of avoiding the inhibitory effect is optimization of the template content to an inhibition-free concentration $^{[3,15]}$.

Roussel et al $^{[\dot{[3]}}$ performed a comprehensive study evaluating different extraction methods and found that the lowest inhibition is observed in samples homogenized by vortexing and purified by commercial column-based kits. They also assessed the inhibitory effect of non-target DNA by amplification of bacterial
$16 \mathrm{~S}$ gene in the presence of $20 \mathrm{ng} / \mu \mathrm{l}$ of MgDNA, which resulted in 30\% inhibition. Moreover, they prepared 1:10 and 1:100 dilutions of MgDNA and observed more than $90 \%$ detection of bacterial $16 \mathrm{~S}$ plasmid DNA in the diluted samples. However, they did not determine the exact concentration of the diluted samples. In this study, we were able to identify three zones, where the amplification of HpDNA was faced with (1) full inhibition (>10 ng/ $\mu \mathrm{l})$, (2) partial inhibition or interference $(0.63-10 \mathrm{ng} / \mu \mathrm{l})$, and (3) no inhibition with $\sim 100 \%$ detection rate $(\leq 0.63 \mathrm{ng} / \mu \mathrm{l})$. According to this accurate assessment, at estimated concentration of $0.63 \mathrm{ng} / \mu \mathrm{l}$ of mouse gastric tissue DNA, HpDNA could be fully quantitated by qPCR. This finding is of particular importance when the ratio of HpDNA to MgDNA is at minimal levels ${ }^{[3,19,20]}$.

Quantitation of Hp copy number in the stomachs of treated mice is an important approach for the evaluation of vaccination/treatment efficacy ${ }^{[16]}$. Our developed method could successfully differentiate mice infected with different doses of Hp inoculums. Furthermore, it was applied for Hp quantitation in immunized vs. sham-immunized mice and could show significant differences between the two groups. Our method could amplify $10^{1}-10^{7}$ and $10^{1}-10^{9}$ copies of HpDNA and PT, respectively. Nevertheless, the Ct of 10 copies did not linearly follow the previous dilutions. Therefore, the quantitation of low Hp copy numbers in the stomachs of colonized mice requires further optimization.

In conclusion, we have hereby developed a method for Hp copy number quantitation, which can bypass the interference and/or inhibition imposed by MgDNA and is able to quantitate the colonizing Hp copy numbers in the gastric tissue, segregating mice inoculated with low vs. high doses of $\mathrm{Hp}$, as well as those immunized vs. controls.

\section{ACKNOWLEDGEMENTS}

The authors would like to thank Drs. Elham Tafsiri and Zana Karimi Kurdistani for their technical guidance. This study was funded by a research grant from Pasteur Institute of Iran, Tehran, Iran.

CONFLICT OF INTEREST. None declared.

\section{REFERENCES}

1. Lascols C, Lamarque D, Costa JM, Copie-Bergman C, Le Glaunec JM, Deforges L, Soussy CJ, Petit JC, Delchier JC, Tankovic J. Fast and accurate quantitative detection of Helicobacter pylori and identification of 
clarithromycin resistance mutations in $\mathrm{H}$. pylori isolates from gastric biopsy specimens by real-time PCR. Journal of clinical microbiology 2003;41(10): 45734577.

2. Loddenkötter B, Becker K, Hohoff C, Brinkmann B, Bajanowski T. Real-time quantitative PCR assay for the detection of Helicobacter pylori: no association with sudden infant death syndrome. International journal of legal medicine 2005; 119(4): 202-206.

3. Roussel Y, Wilks M, Harris A, Mein C, Tabaqchali S. Evaluation of DNA extraction methods from mouse stomachs for the quantification of $H$. pylori by real-time PCR. Journal of microbiol methods 2005; 62(1): 71-81.

4. Molnar B, Szoke D, Ruzsovics A, Tulassay Z. Significantly elevated Helicobacter pylori density and different genotype distribution in erosions as compared with normal gastric biopsy specimen detected by quantitative real-time PCR. European journal of astroenterology and hepatology 2008; 20(4): 305-313.

5. Belda S, Saez J, Santibáñez M, Rodríguez JC, Galiana A, Sola-Vera J, Ruiz-García M, Brotons A, LópezGirona E, Girona E, Sillero C, Royo G. Quantification of Helicobacter pylori in gastric mucosa by real-time polymerase chain reaction: comparison with traditional diagnostic methods. Diagnostic microbiology and infectious disease 2012;74(3): 248-252.

6. Kargar M, Ghorbani-Dalini S, Doosti A, Souod N. Realtime PCR for Helicobacter pylori quantification and detection of clarithromycin resistance in gastric tissue from patients with gastrointestinal disorders. Research microbiology 2012; 163(2): 109-113.

7. Saez J, Belda S, Santibáñez M, Rodríguez JC, Sola-Vera J, Galiana A, Ruiz-García M, Brotons A, López-Girona E, Girona E, Sillero C, Royo G. Real-time PCR for diagnosing Helicobacter pylori infection in patients with upper gastrointestinal bleeding: comparison with other classical diagnostic methods. Journal of clinical microbiology 2012; 50(10): 3233-3237.

8. Applied_Biosystems: Creating standard curves with genomic DNA or plasmid DNA templates for use in quantitative PCR. 2003. http://www.applied biosystems/.

9. Corthésy B, Boris S, Isler P, Grangette C, Mercenier A. Oral Immunization of Mice with Lactic Acid Bacteria Producing Helicobacter pylori Urease B Subunit Partially Protects against Challenge with Helicobacter felis. J Infect Dis 2005;192:1441-9

10. Talebkhan Y, Bababeik M, Esmaeili M, Oghalaei A, Saberi S, Karimi Z, Afkhami N, Mohammadi M. Helicobacter pylori bacterial ghost containing recombinant Omp18 as a putative vaccine. Journal of microbiological methods 2010; 82(3): 334-337.

11. Shafaie E, Saberi S, Esmaeili M, Karimi Z, Najafi S, Tashakoripoor M, Abdirad A, Hosseini ME, Mohagheghi MA, Khalaj V, Mohammadi M. Multiplex serology of Helicobacter pylori antigens in detection of current infection and atrophic gastritis - A simple and cost-efficient method. Microbial pathogenesis 2018; 119: $137-144$.

12. Douraghi M, Saberi Kashani S, Zeraati H, Esmaili M, Oghalaie A, Mohammadi M. Comparative evaluation of three supplements for Helicobacter pylori growth in liquid culture. Current microbiology 2010; 60(4): 254262.

13. Song Q, Haller B, Ulrich D, Wichelhaus A, Adler G, Bode G. Quantitation of Helicobacter pylori in dental plaque samples by competitive polymerase chain reaction. Journal of clinical pathology 2000; 53(3): 218222.

14. Song Q, Haller B, Ulrich D, Wichelhaus A, Adler G, Bode G. Quantitation of Helicobacter pylori in dental plaque samples by competitive polymerase chain reaction. Journal of clinical pathology 2000; 53(3): 218222.

15. Alaeddini R. Forensic implications of PCR inhibitionA review. Forensic scientific international: genetics 2012; 6(3): 297-305.

16. Roussel Y, Harris A, Lee MH, Wilks M. Novel methods of quantitative real-time PCR data analysis in a murine Helicobacter pylori vaccine model. Vaccine 2007; 25(15): 2919-2929.

17. Mikula M, Dzwonek A, Jagusztyn-Krynicka K, Ostrowski J. Quantitative detection for low levels of Helicobacter pylori infection in experimentally infected mice by real-time PCR. Journal of microbiological methods 2003; 55(2): 351-359.

18. Tebbe CC, Vahjen W. Interference of humic acids and DNA extracted directly from soil in detection and transformation of recombinant DNA from bacteria and a yeast. Applied and environmental microbiology 1993; 59(8): 2657-2665.

19. Fischer-Romero C, Lüthy-Hottenstein J, Altwegg M. Development and evaluation of a broad-range PCRELISA assay with Borrelia burgdorferi and Streptococcus pneumoniae as model organisms for reactive arthritis and bacterial meningitis. Journal of microbiological methods 2000; 40(1): 79-88.

20. Cogswell FB, Bantar CE, Hughes TG, Gu Y, Philipp MT. Host DNA can interfere with detection of Borrelia burgdorferi in skin biopsy specimens by PCR. Journal of clinical microbiology 1996; 34(4): 980-982. 